\title{
The Study on the Impact of "Lewis turning point" Approach on the Sporting Goods Industry in China and Countermeasures
}

\author{
Li Chun-Lin \\ (Jinan university sports institute Guangzhou 510632)
}

Key words: Lewis turning point; sporting goods industry; impact; countermeasures study;

\begin{abstract}
. making use of the research methods, such as literature information, survey research, online query etc., discussing about the current status and the existing issues of the sporting goods companies in China in the times of Lewis turning point approach, and specific to the approach of Lewis turning point, this article illustrates its impact on sporting goods industry, and points out that the enterprise must change business and management idea, increase scientific investment and introduce advanced machinery equipment, reduce dependence on labour demands, improve productivity, meanwhile the company needs to actively create self-owned brand of company products, and increase the added value of products, establish the harmonious service relations, taking the development road of intensive management, and effectively coping with the challenges of Lewis turning point approach.
\end{abstract}

\section{Introduction}

Since this year, the factors influencing China's economic development have been constantly increased: the domestic commodity prices generally rise, inflation is continuously intensified and remain high, CPI index is gradually increased monthly, the demand dynamics are still slowing, the complex and serious international economic situation etc., these factors have a severely impact on the development of the sporting goods industry. RMB appreciation is continuous, the RMB revaluation is increased by $3 \%$ last year, this year it will rise at least $5 \%$, this will make many sporting goods enterprises in China attacked, especially the foreign funded enterprise settled in dollars, and the products profits are further compressed, many manufacturers facing the unprofitable risks, even losses and closing. Due to the continuous RMB appreciation, the inflation index is rising month by month, the sporting goods enterprises are facing the dual pressures of rising raw material costs and rising labour costs, it can be said that the main issues that sporting goods enterprises face this year are Lewis turning point approach or emerging. For the sporting goods enterprises that the development power is relied on cheap labour, rather than brand, sales channels, product technologies, it is a serious challenge. How to deal with this challenge and prevent accidents before they occur are the pressing issues that we must face.

\section{The study object and method}

2.1 Research Object: the study of this subject takes the sporting goods industry as research object, combining with sports economics and industrial economics, as well as "Lewis turning point" theory, making a discussion about the impact of sporting goods companies transformation competency and government processing trade policy on sporting goods industry development in China.

2.2 Research methods: literature method, questionnaire method and mathematical statistics method.

2.2.1 Literature method: referring to related newspapers,magazines, relevant statistical yearbook and statistics and so on, providing a basis for the topic and experiments.

2.2.2 Questionnaire method

2.2.2.1 Survey scope, time course and sample selection

This investigation began in February 2011, and the time of finishing the questionnaire design is March, from May to July, we spread investigation within the sporting goods industry groups zone, such as Jiaxing, Ningbo, Shaoxing, Wenzhou,and Guangdong along the coastal areas, the selection 
of the investigation samples use the random extraction method. In August, data entry and preliminary analysis will be completed, in September investigation report is formed.

2.2.2.2 The design and identification of questionnaire

3) Data analysis. The data analysis tool used by this survey is SPSS 17.0 statistical analysis tool.

\section{The study findings and analysis}

\subsection{Lewis turning point and its approach}

3.1.1 The definition of "Lewis turning point"

In 1954, American famous economist Arthur Lewis proposed a concept in population flow model about: " Lewis turning point", that is, it is the turning point that the rural labour force surplus turned to labour force shortage. In his view, the economic development process of developing countries is the modern industrial sector expansion process compared to agriculture, in this process, the labour force of agricultural sector is constantly shifted to industrial sector, until the labour force surplus of agricultural sector is transferred clean. At this time, the wages in labour market have a steep increases, thus the economist called it "Lewis turning point".

\subsubsection{The approach of Lewis turning point}

"Lewis turning point" is the inevitable phenomenon in the economic development process of developing countries, and the related corresponding concept is "demographic dividend", that is , the labour force surplus causes the relative lower costs of labour force elements, which is fully reflected in the economic development model in China. China is a populous country, a large number of migrant worker in cities provide a strong driving force for economic development. However, there is a close relationship between the two phenomenon, the emerging of "Lewis turning point" will cause the gradually disappear of "demographic dividend". This is also consistent with population development law, that is , demographic dividend can not be extended indefinitely, the excessive reliance on cheap labour force advantage can affect the innovation capacity.

3.2 The investigation and discussion about "labour shortage" of sporting goods enterprises in China under the background of "Lewis turning point"

3.2.1 Through the investigation, the enterprise has the following situation: there are widespread shortage of workers in enterprises, the problems with female workers are more than male workers, which is particularly prominent among employees below 35 years of age.

3.2.2 Lewis turning point forces the improvement of recruitment condition. Such as increasing wages, easing enterprise recruitment difficulties; strengthening labour security, and improving the public service system in order to achieve the enterprise recruitment; taking the approach of " going out, and introducing", strengthening collaboration with labour force output provinces;

\section{The impact of Lewis turning point approach on sporting goods enterprises}

\section{1 "labour shortage" directly affects the normal operation of enterprises}

For a long time, sporting goods enterprises in China have been relying on cheap labour, the sporting goods world value chain is embedded from processing link, and actively participating in the international labour division of value chain, undertaking the upstream manufacturers orders, then processing, manufacturing, thus getting a small amount of profits. Especially after the financial crisis, the demand recovery in overseas markets caused the substantial increase of orders in foreign processing enterprises, but the labour supply situation was not improved, it is difficult for enterprises to recruit a large number of workers as needed in a short time, there emerging the idle production lines, export orders could not be completed in time, which seriously affecting the enterprise normal production and operation. There are "labour contractor" phenomenon in specific areas, he is only responsible for recruiting temporary workers, and extracting a certain amount of fee in capita. As we can imagine, how hard the operation of sporting goods companies are now, the orders received so hard can not be finished timely, coupled with difficult financing and loans, they have been the common challenges that the current sporting goods businesses face. 
4.2 The rising labour costs have a directly impact and erosion on business profits

The approach of Lewis turning point means that the times with unlimited supplies of low labour force costs have come to an end, it is difficult for the majority of sporting goods enterprises to hire suitable processing workers at lower wages. Since 2010, the minimum wage standard has been raised through the country, even it was up to $40 \%$ in the coastal areas, coupled with inflation and the price rising of raw material, these will make the business spending costs increasing, while the United States is constantly forcing RMB appreciation, thus the enterprise sales performance plummeted, finally the small profits of enterprises will fall sharply, so that a large number of small and medium-sized sporting goods processing enterprises face the collapse and closing situation.

4.3 Labour disputes are constantly increasing, the business management costs are rising sharply

In conclusion, Lewis turning point approach brings new challenges to China's sporting goods enterprises, how to overcome the labour shortage, rising wages and raw material costs are the main problems of these enterprises needed to be solved at present, only changing the development mode, transforming and upgrading industrial structure, and developing the way of high product added value is the good medicine and recipe

\section{The strategic analysis of sporting goods enterprises dealing with Lewis turning point}

5.1 Improving resource utilization efficiency, forming the effective substitution of capital for labour, and reducing labour demands.

With the approaching of Lewis turning point, enterprises are facing the challenges of labour shortage and rising labour costs, if enterprises want to solve the above problems, they must transform the growth mode that obtaining development through relying on cheap labour, making industrial upgrading and transfer, actively introducing advanced machines and equipments, reducing excessive dependence on labour, replacing labour with capital, improving unit labour productivity, and getting a new competitiveness.

5.2 Carrying out industrial transfer to lengthen the production link value chain.

The approaching of Lewis turning point make enterprises facing " rising costs and workers shortage phenomenon", however, there are vast areas in China, the impacts in eastern and western areas are different, generally the eastern regions is higher than central and western regions, in terms of comparative cost advantage, the production processing link is migrated into lower-cost regions, such as western regions in China, Southeast Asia, at the same time, eliminating the obsolete equipments during the transfer process, and introducing advanced equipment, updating the equipments and upgrading products; its purpose is that when enterprises get the shoemaking orders, they outsource the labour-intensive part to migration areas, they engage in the technology-intensive production by themselves, and achieve the goal of reducing dependence on labour, and improving product added value.

5.3 Strengthening the brand and improving product added value

Firstly, in China, most of sporting goods enterprises are small and medium-sized, their scope is not big, and they have no own brand, they are mainly embedded into global value chains in the way of OEM, and the product added value is relatively low, they obtain the small profits through cheap labour. Therefore, enterprises must change the competition concept and enhance brand awareness, improving the reputation of their products through brand-building, then getting a high added value, and effectively resolving the pressure caused by Lewis turning point. Secondly, the foundation and building of product brand need taking risks, especially for the single enterprise, it is very difficult for them to build a brand by themselves, because it will takes a lot of money invested, and if they develop into the SME alliance, the joint development and use of brand, as well as unified sales, which can make up for this deficiency, therefore, creating regional brands, and giving play to the clustering effect, creating market advantages and developing industrial space, these are all effective ways to strengthen brand. Finally, we must unswervingly taking the road of common development with sporting undertakings in China, we should insist on directional and systematic sponsor of sports events, expanding the brand image, and enhancing brand connotation. Because the 
brand-building need long-term accumulation and unique brand connotation, thus letting the brand enjoyed by popular support.

5.4 Strengthening human resource management of enterprise, and reducing labour disputes to build harmonious labour relations

For a long time, many enterprises have been driven by short-term interests, they are lack of long-term vision, and do not concern about the staff, enterprises always lower the wages of workers and lengthen working hours, the living conditions is poor, these factors make workers can not get their due social security, not only can not workers get the humanistic concern, but also spiritual care, which cause enterprises workforce instable, but under the condition of infinite labour supply, they still can obtain the required labour resources, and maintain normal production activities. However, with the approaching of Lewis turning point, the labour resources is changed into shortage from unlimited supply, it is hard for companies to recruit suitable staff within their wage level standard. Therefore, enterprises must transform operation and management ideas, strengthen human resources management, increase workers' wages, improve the living conditions of workers, increase the social security that worker should have, improve the cohesion force of enterprise staff, try to build a harmonious labour relations between employees and enterprises, ensuring the normal operation of enterprise production.

\section{References}

[1] Hu Zhengliang. " how to treat the Lewis turning point" 【J】 Study on Shandong Economic Strategy, 2010-7:33-35

[2] Bao Xiaozhong. Lewis model and coastal areas with " migrants shortage" [ J ] . Economist, 2010-4: 25-27 